Article

\title{
The Importance of a Dedicated Monitoring Solution and Communication Strategy for an Effective Management of Complex Active Landslides in Urbanized Areas
}

\author{
Daniele Giordan ${ }^{(}$, Aleksandra Wrzesniak * and Paolo Allasia \\ Consiglio Nazionale delle Ricerche-Istituto di Ricerca per la Protezione Idrogeologica, Strada delle Cacce 73, \\ 10135 Torino, Italy; daniele.giordan@irpi.cnr.it (D.G.); paolo.allasia@irpi.cnr.it (P.A.) \\ * Correspondence: aleksandra.wrzesniak@irpi.cnr.it; Tel.: +39-011-3977-829
}

Received: 25 January 2019; Accepted: 11 February 2019; Published: 13 February 2019

check for updates

\begin{abstract}
Over the last decades, technological development has strongly increased the number of instruments suitable for landslide monitoring. For large landslides, monitoring systems are organized in complex and multi-instrumental networks aimed at controlling several representative physical variables. The management of these networks is often a complicated task that must consider technological aspects, data-sets processing, and results publication. We developed a new hybrid system focused on capturing and elaborating data-sets from monitored sites and on disseminating monitoring results to support decision makers. With respect to other available monitoring solutions, we emphasized the importance of technological aspects and a correct communication strategy, which represents the last fundamental step for a correct use of collected data. Monitoring results are often published in a difficult and not user-friendly way because they are intended for technicians with adequate background. Such an approach may be inefficient, especially during emergencies, when also non-expert people are involved. Additionally, this system consists of early warning application, which integrates a threshold-based approach and a failure forecasting modeling. The presented approach represents a possible improvement for a more sustainable management of active landslides that could have a strong impact on population and infrastructures in particular in highly urbanized areas.
\end{abstract}

Keywords: landslide monitoring; early warning; emergency management; dissemination; urbanized areas

\section{Introduction}

Today, the use of monitoring systems to control the evolution of active landslide and their hazard assessment is very diffused [1,2]. In the last decades, the number of available technical solutions and complexity of landslide monitoring networks have been progressively increasing to fulfill the growing necessity of managing large slope instabilities in urbanized areas.

Urban pressure, amplified by climatic changes, has progressively increased the cases in which the evolution of a landslides can have a direct impact on inhabited areas [3]. Several approaches can be adopted to reduce this impact. They may vary according to different factors like the dimension and the typology of landslide and the distribution of infrastructures. The most critical combination is the presence of large landslides in highly populated areas. In these cases, the delocalization can be hard to implement, and the landslide stabilization can be very difficult and not immediate. Often, the only solution is the use of monitoring systems to improve the knowledge of the landslide behavior and to support decision makers during emergencies related to a partial or total collapse of the instable area. 
These systems, if correctly managed, may also create favorable conditions for the population at risk in terms of life comfort.

The adopted monitoring networks are based on the high frequency measurement of the most representative physical variables: (1) superficial displacement, (2) deep displacement, (3) hydro-geological (water table, pore pressure), and (4) meteorological. In the last years, several case studies were analyzed and published, and they represent good examples of this approach. For example in Italy, complex monitoring networks have been developed to control the evolution of landslides such as Ancona [4], Montaguto [5,6], Mt.de La Saxe [7], Rotolon [8], and Ruinon [9]. In other countries, similar approaches have been applied to monitor complex landslides such as Randa (Switzerland-[10]), La Vallette (France-[11]), Super Sauze (France-[12,13]), Sado Island (Japan-[14]), and Slumgullion (USA-[15]).

If we analyze these monitoring systems, we can notice that in all cases the monitoring network workflow consists of (1) on-site data acquisition, (2) data processing, and (3) monitoring result publication and dissemination.

It is evident that technological aspects are predominant in existing monitoring applications, especially in on-site acquisition of representative variables. Starting from Angeli et al. [16], the number of publications dedicated to the technological development of monitoring systems was progressively covering all available technologies, e.g., GPS (Global Positioning System), RTS (Robotized Total Station), GB-InSAR (Ground-Based Synthetic Aperture Radar), and in-place and robotized inclinometers. In the literature one can find the examples of the use of GPS [17,18], RTS [19,20], GB-InSAR [21], and in-place and robotized inclinometers (respectively, [22,23]), among many others.

After on-site acquisition, monitoring systems manage captured data-set and provide representation of the landslide evolution. Allasia et al. [24] and Frigerio et al. [8] present a possible approach for the management of such data-sets. In both cases, informatics tools that are able to acquire, process, validate and store acquired data-sets compose the presented systems. The sequence of these tools makes the on-site acquisition procedures available in a centralized and remote-controlled system. This also allows simultaneous management of several monitoring systems and control of different landslides.

As mentioned before, complex landslides are usually monitored by multi-instrumental networks. These networks provide many types of time series, which are later integrated in a combined database. The integration of different instruments in a unique centralized system, which bypasses applications developed by the producers of monitoring instruments, is a key point for an efficient management of complex monitoring networks [24].

Additionally, the data processing is usually linked to the management of early warning thresholds $[25,26]$. The adaptation of monitoring systems to early warning purposes is an optimal solution that may facilitate a correct management of landslide acceleration phases [27-30].

Often, early warning systems (EWSs) are associated with superficial displacement, which is probably one of the most frequently used parameter to describe movement tendency and overall knowledge of landslides [31,32]. However, EWSs design and in particular a priori definition of related thresholds is one of the most important and critical aspect of landslides monitoring systems [33]. This is mainly due to the complex and unpredictable behavior of natural hazards, which often results in large number of variables involved [34].

Thresholds are often established by performing back analysis of the available monitoring data. They can be also determined by considering similarities to other events or by following numerical approaches as proposed by Crosta and Agliardi [34]. However, this action may be hampered by insufficient knowledge of the monitored landslide and by the numerous factors (e.g., geotechnical parameters of the shear surface or real effect of pore pressure) [35].

Carlà et al. [36] proposes to use inverse velocity method for setting alarm thresholds and forecasting landslides and structure collapses. In fact, the time of failure forecasting became a major subject of many researchers. The successful work of Saito [37] and Fukuzono [38] inspired many other 
authors to develop different approaches in order to estimate time of failure (ToF). A summary of the different methods proposed in literature can be found in Federico et al. [39]. These studies introduce simplified empirical and/or graphical methods based on the assumption that material, under constant stress condition, follows a creep mechanism before rupture.

In the past, the monitoring data-sets were exclusively dedicated to technicians with a specific background. This was because the common representations of measured quantities were not user friendly. According to our experience, the use of complex representation limits the number of people that can handle this information [40].

As described in Giordan et al. [41], the large landslides emergencies are often managed by multidisciplinary teams. These teams are usually composed not only of technicians, but also of local authorities who often do not have an adequate background on landslide monitoring. The presence of people with various backgrounds obliges the developer of monitoring systems to consider how to share available information. Often, the importance of a monitoring results communication strategy is underestimated. During emergencies, when time is limited, an easy access to available information could help taking adequate decisions about the safety of people and goods. In this context, the dissemination of monitoring results has become a crucial element of the emergency management.

The experience acquired during the development of the software for management of landslide monitoring data called ADVICE (ADVanced dIsplaCement monitoring system for Early warning) [24] lets us realize that a correct use of monitoring results cannot be limited to a simple near-real time application that publishes the monitoring results on a dedicated webpage. To obtain an effective system that can be used for a more sustainable management of large slope instabilities in urbanized areas, it is mandatory to develop a more complex approach that merges the management of data with the use of thresholds for EW purposes and dissemination procedures that assure a correct communication to stakeholders. In order to fulfill these requirements, we developed a multidisciplinary solution for an effective management of landslide monitoring systems called LANDMON (LANDslides MOnitorng Network). Over the years, we have developed a set of automatic modules that governs in near-real time the management process from data acquisition to results dissemination. Additionally, this system consists of early warning application, which integrates threshold-based approach and failure forecasting modeling. LANDMON emphasizes a proper monitoring data representation and dissemination, due to the heterogeneity of actors involved in the hazard management process. Therefore, LANDMON is an example of innovative solution that integrates technical and modeling features with communication strategy aimed at supporting decision-makers and population at risk, in particular during emergencies. This approach represents a possible improvement for a more sustainable management of monitored active landslides that could have a strong impact on population and infrastructures.

\section{Methods}

Figure 1 summarizes the workflow of LANDMON, which is divided in three main phases. The first phase is composed of data acquisition procedures, the second one is composed of early warning applications and the third one regards monitoring results representation and dissemination. 


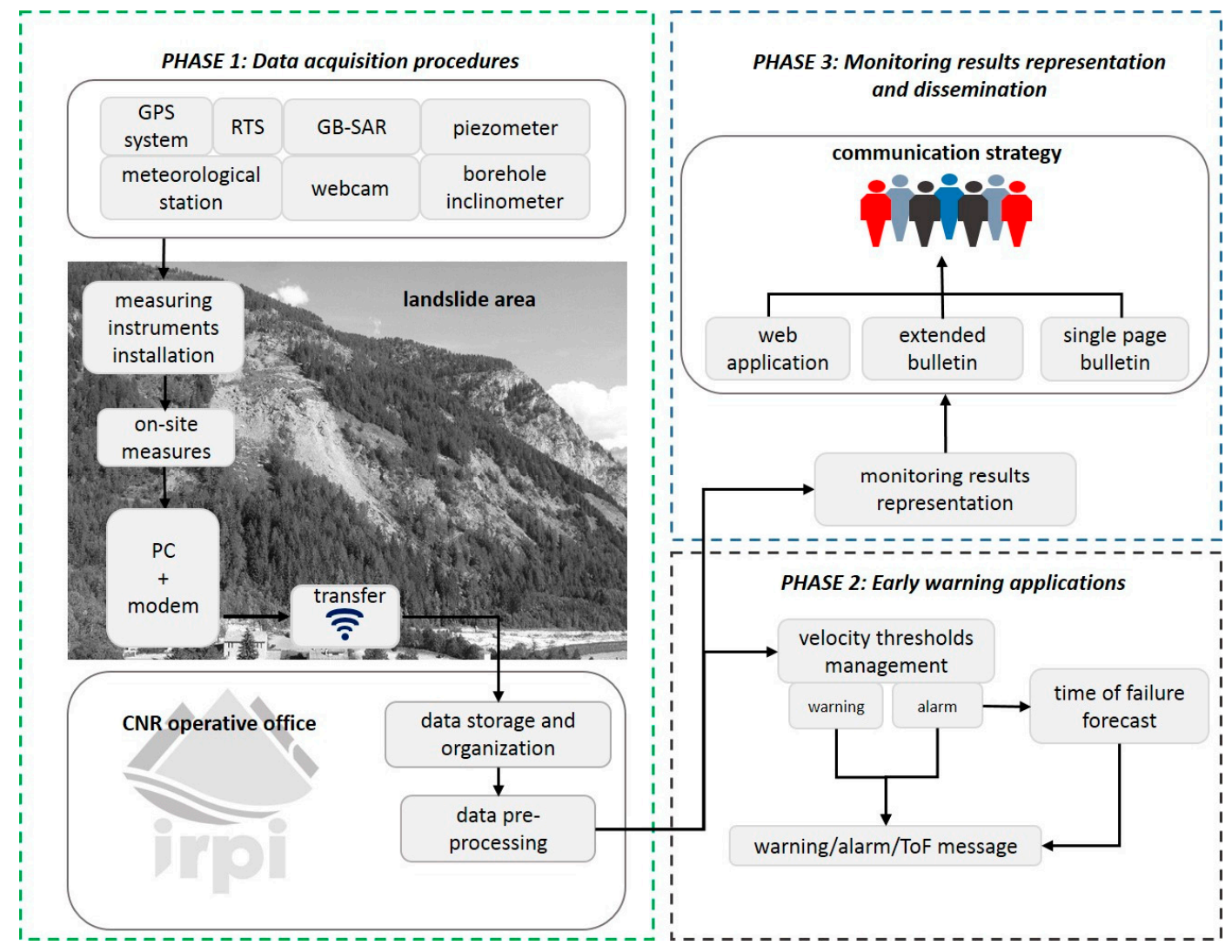

Figure 1. LANDMON (LANDslides MOnitorng Network) structure. The workflow is divided in three main phases: (1) data acquisition procedures, (2) early warning applications, and (3) monitoring results representation and dissemination. Photograph: Mont de La Saxe landslide (Aosta Valley, northern Italy).

Every phase has a sequence of procedures that corresponds to LANDMON modules. Each module has a specific purpose and application. The organization in modules, not in a single unique procedure, is important because the system can be freely adapted and activated according to the landslide features and the aims of the monitoring system. One of the most important element of the developed system is that we combined a sequence of tools able to efficiently acquire, analyze, and represent the monitoring data-set from complex networks in a single, complete, and self-contained software with an appropriate dissemination procedure of monitoring results.

The developed system exploits the experience of ADVICE [24] adding new modules and a dedicated communication strategy. ADVICE was a near-real time software for landslide monitoring and early warning threshold management.

In this new version, we improve the classical concept of early warning by integrating a failure forecast module. This module employs inverse velocity approach to forecast time to failure in near-real time [42], and it is automatically activated when a predefined displacement threshold is exceeded.

Beside technological and computational aspects, LANDMON satisfies a predefined communication strategy, which considers a specific approach for monitoring results dissemination [41,43]. The experience in the use of monitoring systems to manage emergencies emphasizes the need for a more effective communication approach to inform stakeholders and involved population correctly. We consider monitoring results dissemination as an essential aspect in the development of monitoring systems. Such an approach improves the effectiveness of these systems during emergencies. At present, most of the commercial applications provide exclusively data acquisition, elaboration and classical results publication (i.e., tables or time series plots). Additionally, only some of them merge data-set from 
different monitoring systems and produce bulletins or other solutions aimed to inform population about landslide evolution and related risk level.

Our approach, unlike existing possibilities, is a multidisciplinary solution for efficient hazard management based on series of informatics tools and on particular strategy for the results communication. The proposed system is also human-centered, because it unifies science, monitoring technology, levels of government and pubic [44-46].

We were progressively developing LANDMON and we applied it to several emergency scenarios [47]. In particular, the most important applications are the Montaguto landslide [5], the Costa Concordia wreck [48] and the Mont de La Saxe landslide [49]. In the following, we present the main features of the three phases.

\subsection{Phase 1: Data Acquisition Procedures}

As introduced in Figure 1, the first phase concerns data acquisition procedures i.e., measuring instruments installation, on-site data acquisition, data transfer, storage and organization, data pre-processing. This structure should be operative for every monitored site and be ready to acquire data from different instruments.

It is fundamental to point out that an innovative system should be able to work with data-sets obtained from different types of instruments installed in the monitored area: RTS, GPS, GB-InSAR, piezometers, meteorological stations, webcam, borehole inclinometers and other geotechnical instrumentation as clinometers and extensimeter. The network composition depends on monitoring scenarios, needs and economic issues. Usually, an accurate planning of the monitoring network is needed, especially in the case of phenomena with heterogeneous directions and velocities of the moving mass. As a consequence, appropriate network design leads to well-organized and efficient monitoring system precisely representing the kinematic of the monitoring area, and to success in hazard management process.

Once the network is ready, the measurements are performed cyclically. For every cycle, the measurements are acquired at certain date and time. The management of instruments acquisition is usually managed via ad-hoc proprietary software arranged in a base station positioned directly at the monitored site. These on-site applications control: (1) frequency of cycles acquisition, (2) acquisition parameters of the instrument, (3) on-site database, (4) export process to obtain a correct data output. The measurement output (its structure and content) depends on used instrument. This output usually is text file containing principal data that describes motion, e.g., displacement in three-dimensional space $(x, y$ and $z)$ in the case of GPS, or vertical and horizontal angles and distance in the case of RTS. The local export of new measurement cycle terminates the on-site acquisition.

Every time a new data-set is available, the system transfers it from local monitoring system to the central server. An internet connection is required in order to transfer and guarantee a continuous flux of these data. This connection may be provided through GPRS (General Packet Radio Service), UMTS (Universal Mobile Telecommunication System), LTE (Long Term Evolution), dial-up or dedicated backbones. The transfer can be done using a dedicated software that uploads the newest file from the local station to the remote server or the local control station may be queried directly from the remote server, and transmitted automatically by secure transfer protocol.

Transferred data are uploaded and stored on a dedicated database server for further elaboration. This step is composed of several actions. First, the raw data is converted into correct metric-scale and coordinates system depending on the technical specification of the instrumentation used. For every instrument a dedicated import tool was developed to transform the original data output from monitoring system in a correct data input for LANDMON. This transformation is fundamental for multi-instrument interoperability. The use of the same time format and coordinate system facilitates the comparison of data-sets registered by different instruments. Then, the data-set is filtered and validated by removing inconsistent data, noisy measurements, spikes, and by handling missing values. 
The elaborated data-set (in the form of input file) is then stored in an unique database that contains all the data acquired at the same monitored area by different instruments. The most recent measurements are integrated with the previous ones in the database. When the sequence of measurements is ready, the data can be analyzed by the modules dedicated to displacement threshold management, failure forecast and visualization.

\subsection{Phase 2: Early Warning Applications}

The early warning application developed in LANDMON is composed of two modules. The first one uses velocity thresholds and defines explicitly the warning level based on the historical monitoring data. While the second one uses inverse velocity approach to forecast the probable temporal distance before the collapse. The first module analyses the velocity in a predefined lapse of time with respect to predefined thresholds [50]. The second module evaluates the propensity to the failure using the inverse velocity approach proposed by Fukuzono [38]. These modules, in near-real time, acquire the last measurement session, process the available data-set and produce adequate warnings.

\subsubsection{Velocity Threshold Management Module}

Design of early warning systems usually starts from defining three levels of attention [26]: (i) ordinary level, when there is no emergency due to the displacement level below predefined threshold, (ii) warning level, when the mass movements oscillate above seasonal perturbations, (iii) alarm level, for critical activation of the unstable area. In our approach, these stages are associated to predefined velocity thresholds. When the velocity limit of warning/alarm level is exceeded, the integrated algorithm of EWS automatically sends alert/alarm messages, e.g., via SMS and/or email to the responsible authorities. After warning, the authorities have often to decide about the activation of specific civil protection procedures. According to the location and possible evolution of the monitored phenomenon, these procedures may include interruption of roads and railway traffic, evacuation of facilities located in the risk zone, and every kind of actions aimed at providing overall safety. The check of thresholds exceeding is executed in near-real time every time new measurements are available. The algorithm checks the warning status based on the last monitoring result, and if the threshold level is exceeded, it activates the predefined procedures to alert decision makers about the current landslide status. This module has been tested under various critical conditions. For example, we applied it during the critical phase of the Mont de La Saxe rockslide occurred in 2014 to support the landslide management team [49]. For further details about Mont de La Saxe landslide see Crosta et al. [7,51] and Alberti et al. [33]. This module was regularly updating decision makers on the evolution of the slide during the most active phases via SMS and with displacement graphs via email. Thresholds were verified for each new measurement session (every hour). SMS and emails were sent every time landslide activity changed. Bulletins were issued weekly, but in the most critical period, they were issued daily.

\subsubsection{Near-Real Time Failure Forecasting Model}

As described before, EWSs are usually composed of three levels of attention. These levels are determined according to directly measured values of the moving mass. Consequently, this imposes underestimated values for the alarm level, in order to maintain a proper margin of safety. Unfortunately, this approach does not provide any kind of prediction about possible evolution of the landslide, making a classical EWS incomplete and sometimes inefficient. In such a case, the time between the alarm level and the eventual failure (partial or total) is unknown. This fact may be inconvenient for authorities and decision-makers who are in charge of management of emergency scenarios, and who are responsible for the safety of humans and/or public wealth. In this context, the use of modeling techniques seems to be a reasonable solution to estimate eventual ToF of landslide phenomena.

Starting from Fukuzono method, we proposed a new approach to forecast ToF by considering near-real time monitoring [42]. Fukuzono approach, also known as the inverse-velocity method, 
uses the evolution of inverse value of surface velocity $(\mathrm{v})$ as an indicator of the ToF by correlating the failure with $\mathrm{v}^{-1}$ tending to zero [38].

Large landslides during their final stage of failure often follow abrupt evolution that correspond to the tertiary creep behavior. Under such conditions, especially when human lives come into play, it is very important to choose a method with quick implementation, calculation and use. Fukuzono method has an easy and efficient approach, and therefore, due to its simplicity, it is suitable for EWSs and it was integrated in LANDMON to model ToF.

Our model takes the advantage of near-real time data acquired from the monitoring network system. We combine inverse-velocity method, interpolation techniques and statistical methods. In particular, we apply linear regression analysis to describe the function of inverse velocity Iv by fitting its discrete points using the least square approach. According to the mentioned Fukuzono method, the root of the resulting equation of the linear regression provides an estimated ToF. This procedure is then repeated for N-times by means of bootstrap re-sampling procedure [52]. Therefore, we can define the confidence intervals, considering $5 \%$ and $95 \%$ tiles among $\mathrm{N}$-times estimations of ToF. In addition, the accuracy of linear relation between the model best fit and the data is verified by calculating the Pearson correlation coefficient CC. For more details, the reader may refer to Manconi and Giordan $[42,49]$.

Presented failure time estimation approach uses confidence intervals ( $5 \%$ and $95 \%$ tiles) to describe time range for the highest probability of failure, and normalized CC values to describe reliability R of the computed forecast model. We have used this reliability value (in percentage) to define additional threshold for LANDMON EWS as an auxiliary support for early warning purposes. For example, when $\mathrm{R}$ is sufficiently high, automatic message for expert operators can be generated.

Figure 2 introduces the adopted concepts for EW, which couples threshold-based EW and failure forecasting. A hypothetical velocity evolution of the landslide point (see the curve on Figure 2) presents a commonly observed landslide behavior toward failure, and it is plotted together with the elements of developed EW (alarm and warning limits, model reliability thresholds).

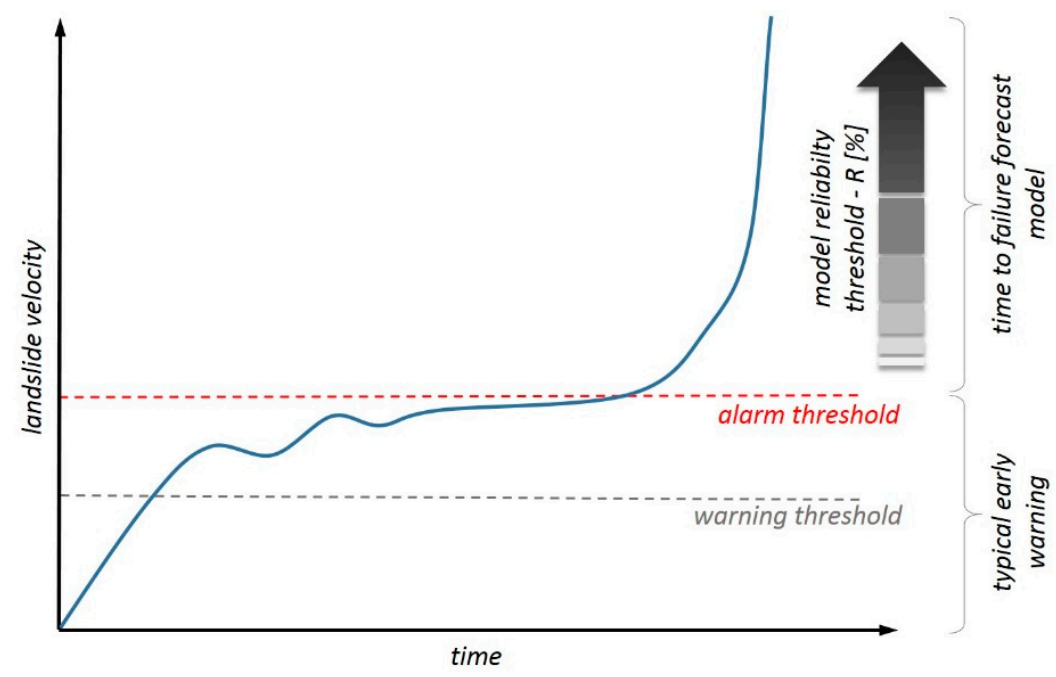

Figure 2. Schematic representation of the adopted approach for early warning applications: coupling threshold-based EW and failure forecast model. The curve presents a hypothetical velocity evolution of the landslide point, which represents usually observed behavior toward failure. The figure adopted from [49].

To exploit ToF results and to make possible the use of thresholds, we adopted the value of reliability $\mathrm{R}$ in the EW system. $\mathrm{R}$ is a good indicator of the forecast estimation and for this reason it can be used to check if the forecast gives a high probability of failure. For example, during Mont de La Saxe emergency scenario in April 2014 [49], we considered a number of R ranges, as follows: (i) for $50 \%<\mathrm{R}<60 \%$ the model reliability is low, failure is unlikely but the situation must be surveyed; 
(ii) for $60 \% \leq \mathrm{R}<75 \%$ model reliability is medium, a failure within the estimated ToF range starts to be likely; (iii) for $75 \% \leq \mathrm{R}<90 \%$ model reliability is high, a failure within the estimated ToF range is likely; (iv) for $\mathrm{R} \geq 90 \%$ model reliability is very high, a failure within the estimated ToF range is highly probable.

The method application is presented in Figure 3. It is an example of real computation that was performed on 16 April 2014 during the Mont de La Saxe emergency. On Figure 3A we present a one month velocity evolution of five prisms, and on the following plots (B, C and D) the forecasting results for the prism $B 4$. The model reliability $\mathrm{R}$ can be obtained for several calculation time windows (CTWs, data acquired over last $12 \mathrm{~h}, 24 \mathrm{~h}, 48 \mathrm{~h}, 1$ week, etc.). Plots B, C and D show the results of our methodology for three CTWs, respectively 7-days, 2-days and 1-day.
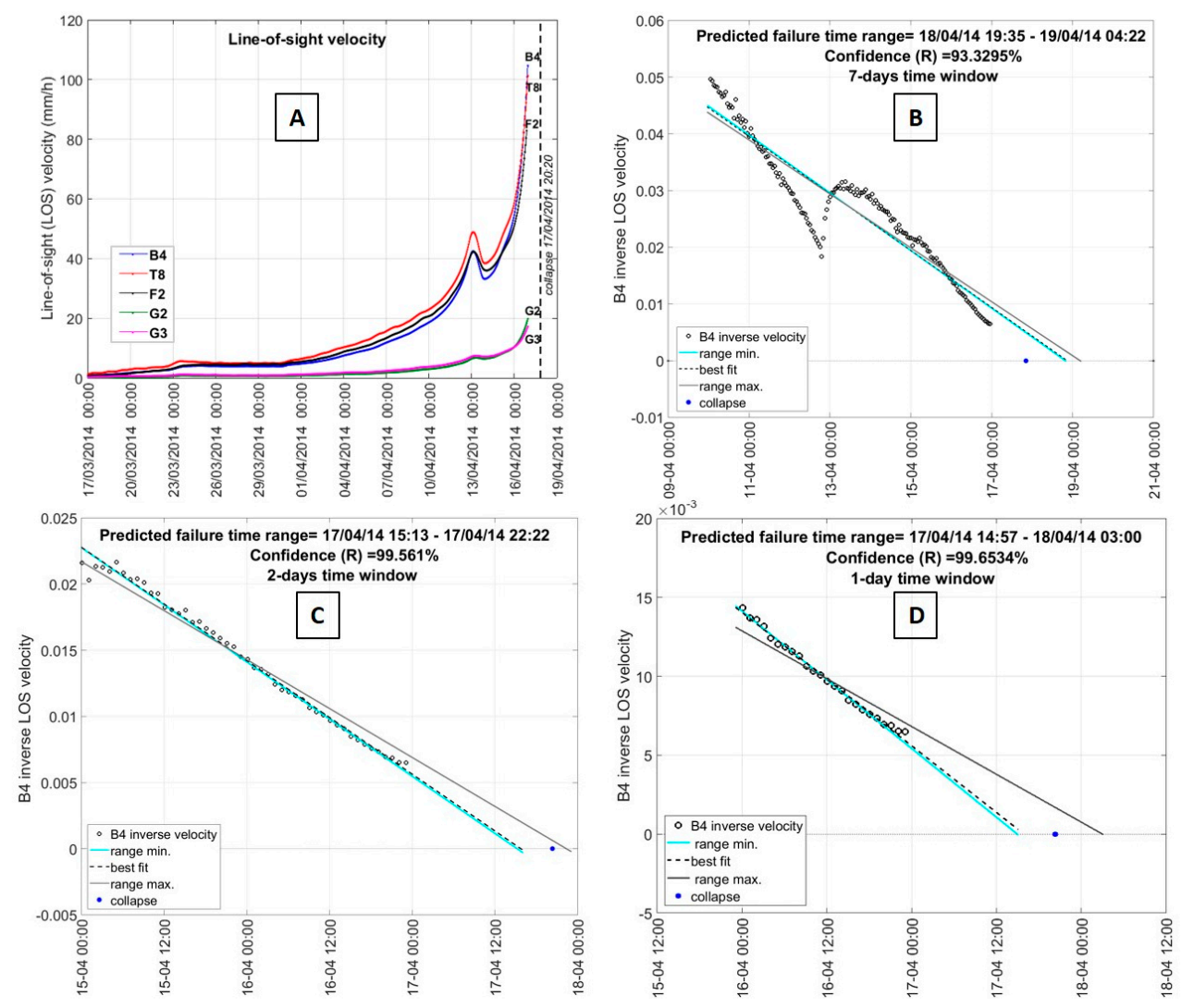

Figure 3. Mont de La Saxe landslide inverse velocity computations. One-month velocity evolution of five prisms (image A), failure time range forecasting and corresponding model confidence $\mathrm{R}$ obtained for seven-days CTW (image B), for 2-days CTW (image C) and 1-day CTW (image D).

As output, the algorithm provides predicted failure time range, best fit and confidence of the model. Additionally, we marked the moment of the real collapse of the landslide, in order to present the efficiency of this approach. In conclusion, the results of the presented procedure can be summarized as follows: if the landslide velocity keeps increasing as in the last calculation time window, the probability of a failure within the estimated time of failure is equal to the model reliability.

If the landslide evolution follows the law of creep, the use of ToF can be a great support for decision makers because it gives not only a description of the actual status as velocity thresholds provide but also a forecast. The indication of possible evolution can be an important information for managing the civil protection procedure. The resulting time of failure is shared exclusively with experts, who are qualified to interpret this result, to evaluate the level of reliability and to exploit it during the most critical phases of emergency. 


\subsection{Phase 3: Monitoring Results Representation and Dissemination}

Usually, monitoring data are presented in the form of tables or time series plots. These typologies of representation may be clear for experienced people who are familiar with monitoring data. However, natural hazard management process involves directly also non-expert people and such data representations may be difficult to interpret, especially for population who is the terminal of this process. For this reason, in addition to time series plots of measured quantities (displacement, precipitation, temperature), we have developed an illustrative approach (@3DA) to represent the monitoring results, i.e., surface displacement representations in 2-and 3-dimensional space and three-dimensional arrows showing real direction of motion [40].

(C)3DA represents surface displacement as magnitude maps by interpolating the punctual monitoring data-set over the given Region Of Interest (ROI). Moreover, @3DA visualizes the measured displacement by means of 3-dimensional arrows at initial measurement points. Such a representation shows magnitude, intensity and direction of displacement measured at this particular point. The referenced results of @3DA algorithm can be projected on various representations of the monitored area, e.g., digital terrain model (DTM), ortho-photograph, perspective photograph, image obtained from Google Earth/Google Maps or from any other service. The advantage of having many possible backgrounds is the possibility to identify the best representation.

C3DA, integrated within LANDMON, can automatically produce the magnitude maps few minutes after each measurement session, which is an important characteristic especially during emergency conditions. Thanks to the configurability of C3DA subroutine, this approach can be easily adapted to the hazard conditions under study. C3DA can be considered as an incipient of the developed and later adopted in LANDMON communication strategy. The aim of this strategy, described in the following section, is a correct and effective dissemination of monitoring results.

The main element that we consider for the definition of our dissemination strategy is the different background of stakeholders, which requires a different approach for the communication of available monitoring results. The dissemination of monitoring results, which is often underestimated by engineering geologists, is extremely important in particular during emergencies, when the time for making a decision (like evacuation or other important actions oriented to damage limitation) is limited.

All monitoring network management solutions consider, after the measurement session, in near-real time a data post-processing and the on-line publication on dedicated website. Accredited users may consult the monitoring results few minutes after the measurement session was completed.

In our system, the latest update of monitoring results is highlighted on the website in a synthetic form, providing a rapid and effective overview of the status of the monitored phenomenon. Content of presented results depends on the characteristics of installed monitoring network. However, the most common data are webcam view, meteorological data (e.g., precipitation and temperature plots), C3DA elaborations, and time series plot of quantities measured by installed instrument (e.g., RTS, GB-InSAR, GPS). The users may also explore results history by selecting a predefined period (day, week, month, or total) or to use an interactive application to plot desired period.

Our dissemination strategy considers the on-line publication of monitoring results and the use of bulletins. According to United Nations studies, each EWS must be human-centered [44,45], considering either emergency condition or educating population at risk, so that response to warning is efficient. For this purpose, we developed a single-page informative bulletin dedicated to non-experts. The aim of this bulletin is supporting decision-makers and informing the population. Inside LANDMON, the bulletin is generated automatically through the bulletin generator tool, which is compatible with every point measurement data set e.g., target displacement provided by RTS, GPS, or GB-InSAR. An example of such a bulletin is shown in Figure 4. For more details about synthetic bulletin and automatic generation procedure, the reader may refer to Wrzesniak and Giordan [43]. 


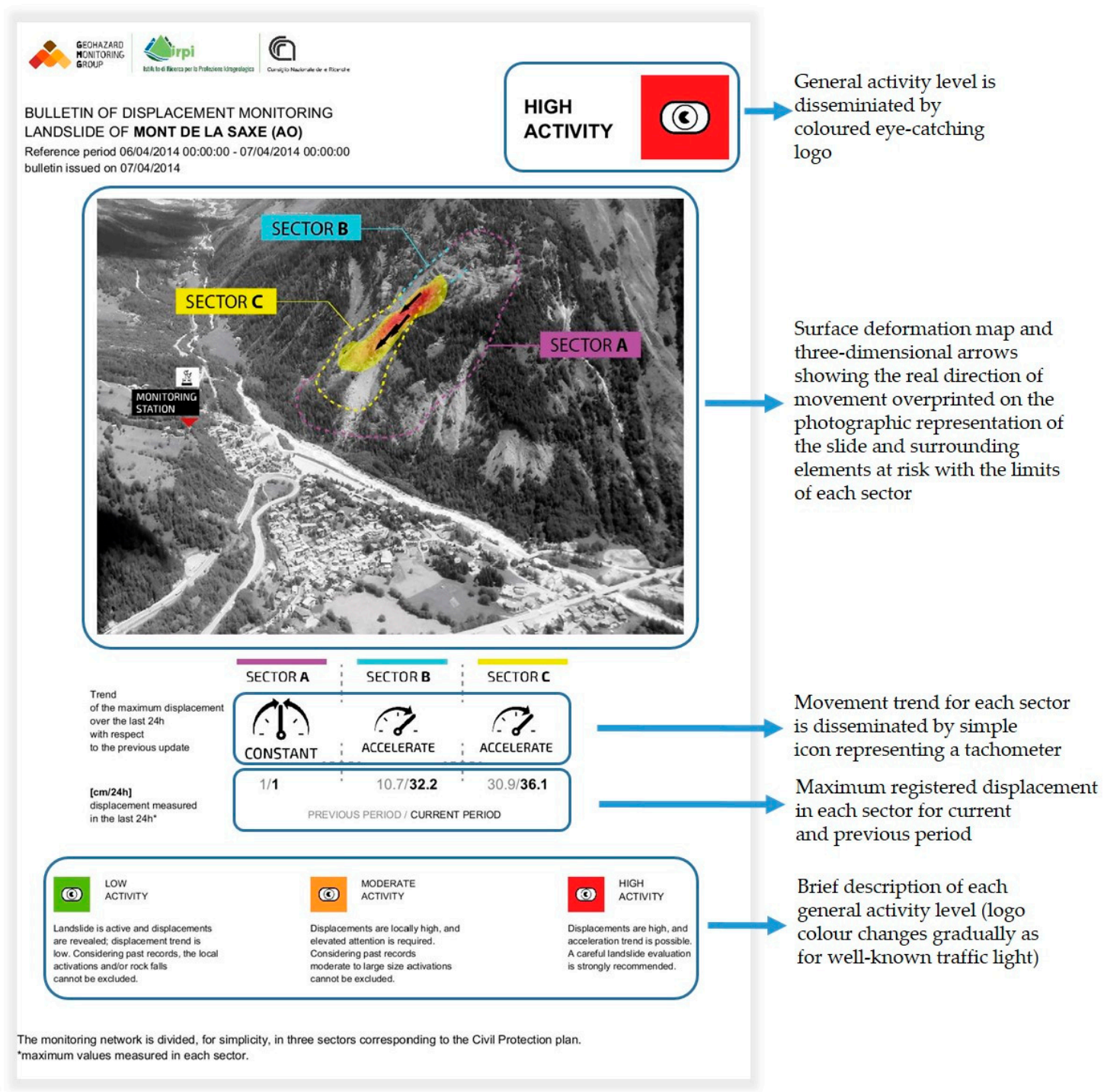

Figure 4. Example of daily single page bulletin. This bulletin was automatically generated based on the real data-set, relative to RTS (Robotized Total Station) measurements of the period 6-7 April 2014. The figure adopted from [43].

The possibility to configure input data and parameters of the algorithm makes this tool flexible and quickly applicable for various scenarios. This tool can operate in near-real time generating the bulletin either continuously with desired frequency (every month, week, day or every $12 \mathrm{~h}$ ) or within EWS (when the threshold is exceeded the bulletin is generated and attached to the warning message).

In general, the main difference between bulletins and time series of other graphics published on-line is that bulletins are not a simple representation of last monitored data, but an analyzed and commented representation of the landslide activity.

\subsection{Communication Strategy of Landslide Monitoring Results}

As mentioned before, one of the most important element that we considered for the definition of a correct communication strategy are needs and background of stakeholder. In order to adopt a "usable science" approach [53], owners of monitoring data are responsible not only for a correct acquisition and analysis, but also for a correct dissemination of obtained results. The correct dissemination makes the difference between a simple monitoring data management and an effective support to decision-makers and population in particular during emergencies. In Giordan et al. [41] and in Wrzesniak and Giordan [43], we proposed the identification of different groups of people, according 
to their role in the emergency management and their background. In particular, we determined four group-types: GROUP-1, GROUP-2, GROUP-3, and POPULATION. The identification of characteristics of stakeholders in terms of background and needs is fundamental for a correct definition of the best communication procedure. In the following a brief description of different defined groups.

GROUP-1 is dedicated to government members (mayor, council members, politicians, etc.). They are usually responsible of the final decision regarding the overall safety. However, their technical background on natural hazards can be limited, so they need a clear overview of monitoring results and current risk level. They also speak to the population, they alert the public about the immediate risk, and they run educational programs to increase risk awareness among the population. The need of this group is a simplified description of the recent landslide evolution and the actual risk level.

Engineers, geologists, and technicians (for example Civil Protection Agency members) are assigned to the GROUP-2. They have a necessary background and experience in order to perform technical analysis and to support GROUP-1. The need of GROUP- 2 is a detailed description of landslide evolution, actual warning level, and last results of failure forecast model.

GROUP-3 is composed of experts, mainly engineers and geologists, who are highly specialized in hazard monitoring and EWSs. They are responsible of development and efficiency of monitoring networks and of data analysis, validation, and elaboration. For this reason, they need direct access to raw data to check that the system is working correctly.

As POPULATION, we consider all people indirectly involved in the emergency management. The correct involvement of population is mandatory for they correct perception of the risk level due to the landslide evolution. Only a well-informed population will response correctly during the most critical phases of the emergency.

After defining the main groups' characteristics, we identified one of the most important goal of our communication strategy, which is how we can communicate monitoring results to stakeholders.

Figure 5 shows a schematic representation of the relationship between dissemination, complexity, and comprehension of monitoring results representations with respect to the identified groups. For example, it is shown that there is a direct relationship between the ability of each group to understand monitoring data and the number of members of this group. In this image, GROUP-3 is an end-member because it is often composed by a few people with a dedicated background and the ability to understand even the most complex representations. On the opposite side of the scheme, the other end-member is the POPULATION, which is the largest group of people. Even if the background may vary in this group, we have to consider them to have a limited ability to comprehend landslide monitoring results. For this reason, this group needs to be informed with simplified representations. If such simplification of results communication is not provided, the complexity of adopted representations could hamper the comprehension of the real level of risk and reduce the propensity of the population to cooperate.

To fulfill these necessities, we adopted in our strategy the @3DA approach [40] that has been developed to represent of the same data-set in many ways with different levels of complexity. In Figure 6, three possible representations of the same RTS data-set are compared. In particular, in images $\mathrm{A}$ and $\mathrm{B}$, the data are presented as surface deformation maps with three-dimensional arrows, and as time-series plot of line-of-sight displacement in image C. In image A, a perspective photograph of the landslide is used as a background. This representation is particular effective for population because it represents a simplified representation of the slope and of the actual instable area. Image A also provides a geographic location of the active parts of landslide, which may facilitate overall understanding of the situation. For this reason, the representation in image A is destined to GROUP-1 and POPULATION. 


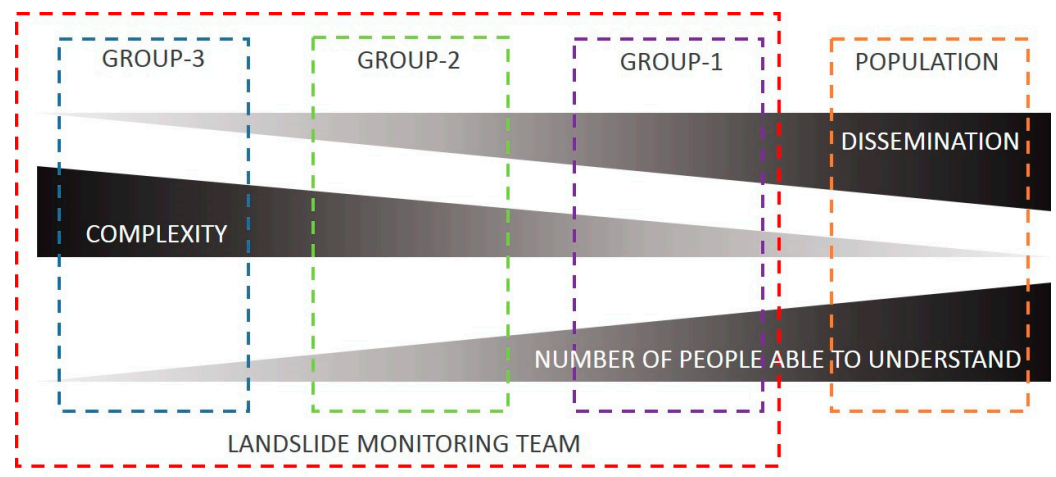

Figure 5. Schematic representation of the relationship between the amount of people to be informed (dissemination process), the complexity of monitoring results representation, the number of people able to understand it and Groups. GROUP-1, -2 and -3 are directly involved in the landslide management and they compose landslide monitoring team. Population is indirectly involved in this process.

Representation presented in image B is more suited for GROUP-1 and GROUP-2. It provides the distribution of landslide activity and the elements at risk (e.g., civil houses, public buildings, transportation structures) thanks to a broader ortho-photograph used as a background. Image $C$ is mainly dedicated to GROUP-2 and GROUP-3 because it requires specific knowledge and experience in landslide monitoring to understand the real meaning of this representation. However, if correctly interpreted, this image is the most representative for the comprehension of the evolution of each single measured target and for the relation between the recent movement rate and the threshold.

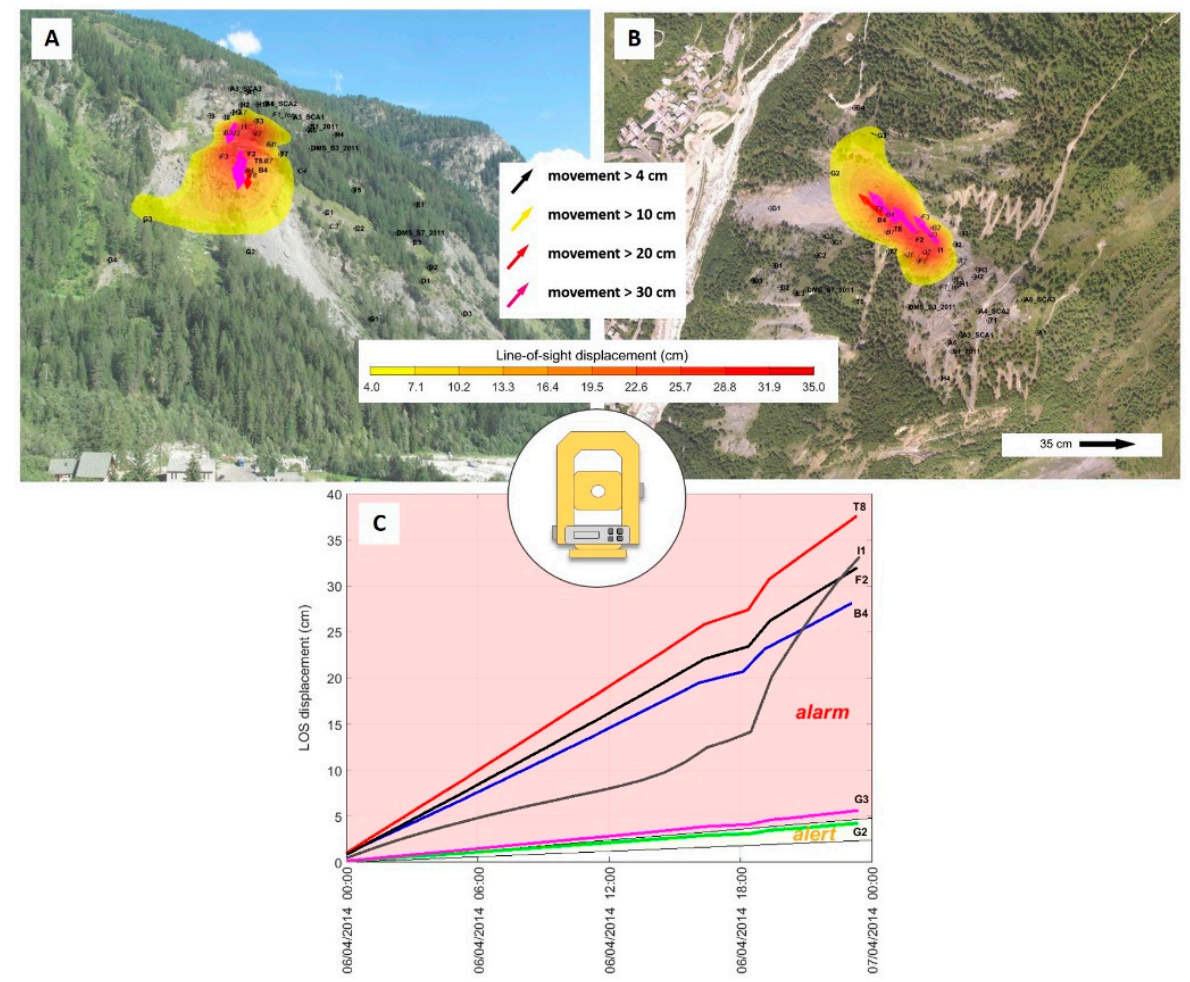

Figure 6. Examples of different representations of the same data-set. The used data are relative to RTS measurements for the period 6-7 April 2017 for Mont de La Saxe landslide. Surface deformation maps (based on line-of-sight displacement) and three-dimensional arrows (based on displacement measured in three directions) are overprinted over frontal view of the landslide (image A) and over ortho-photograph of the landslide with neighborhood area (image B). Image C presents time-series of line-of-sight displacement of the measured targets with warning and alarm zones. These plots are generated by @3DA. 
Another important element that we adopted in our communication strategy is the simultaneous use of near-real time results representation on the website and periodical bulletins, as presented in Figure 7. Our system is able to manage automatically a large flux of monitoring data, from their acquisition to the on-line publication. From the communication point of view, this possibility plays an important role in hazard management, because it can provide a fast and effective update of the latest monitoring results. LANDMON is able to provide an update of monitoring results few minutes after the measurement and processing session is completed. The main limitation of infographics and plots published on the website is the lack of comments and interpretations, which are a key element of adopted bulletins.

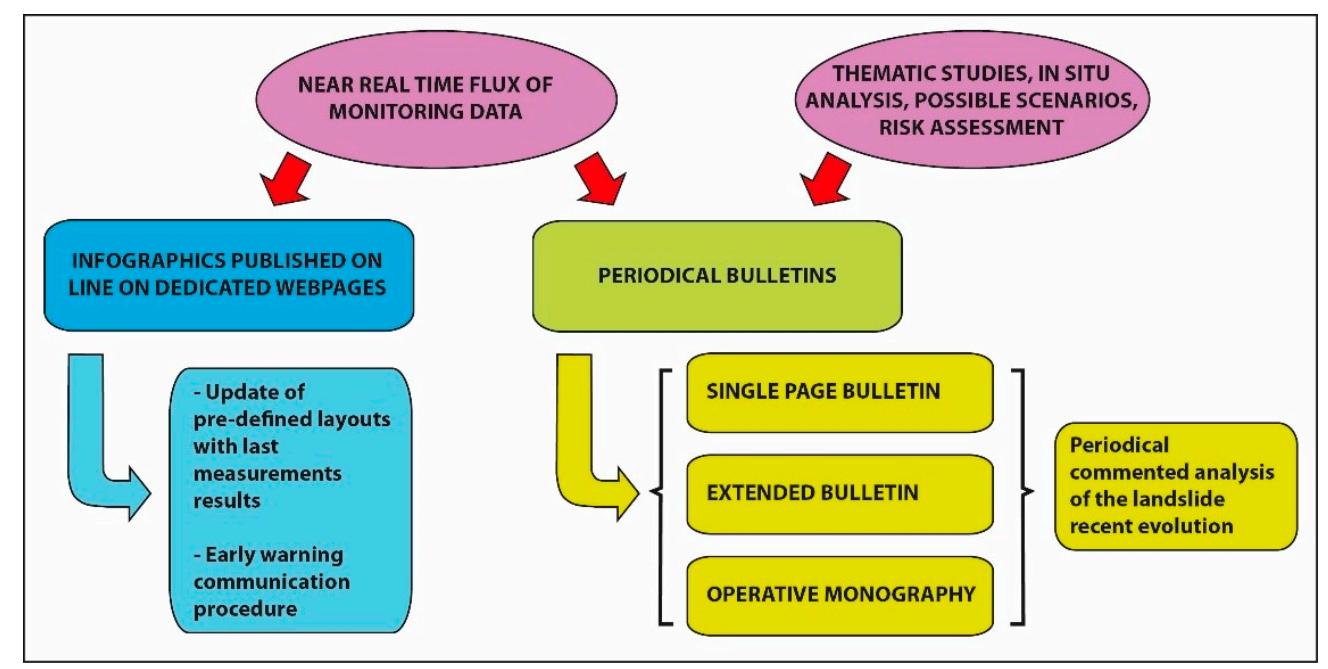

Figure 7. Flowchart of proposed communication strategy based on infographics published on the website and on bulletins.

Decision-makers usually need also a detailed analysis and interpretation of available dataset and that is why we adopted in our communication strategy also different periodical bulletins. We defined three different types of bulletins that contains a different quantity of information and have different communication targets: (i) single page bulletin, (ii) extended bulletin, and (iii) operative monography.

The single page bulletin was described in the previous chapter and it is mainly dedicated to people with limited experience in landslide monitoring (GROUP-1 and POPULATION). This simplified version is the most effective way to communicate the recent level of monitored landslide evolution.

The graphic layout of single page bulletin was designed with special focus on communication aspects so the monitoring results are presented in clear, illustrative and quickly interpretative manner. To achieve this goal, we used infographic techniques to integrate variety of information relative to landslide evolution. Infographics visualize complex data or information in illustrative form, which can be easily understood by the audience [54]. This bulletin presents current displacement status in the form of magnitude map of analyzed physical quantity with three-dimensional arrows associated at the targets location showing the real direction of the motion; all these components are overprinted on the photograph representing monitored area (see Figure 4 for an example). Additionally, we provide information about movement tendency and general activity of monitored phenomenon, and we present them by means of infographics. The bulletin algorithm analyzes the numerical data-set and translates the results into appropriate graphical representation, which is an optimal solution for straight forward communication, especially to non-expert people, e.g., three-dimensional displacement into an arrow, displacement trend into a simple tachometer icon, activity level into an eye-catching logo colored with traffic light graduation (see Figure 4 for these elements).

The extended bulletin is a more detailed and complex version of the single page bulletin. This highly detailed bulletin contains all the available data collected in a defined time interval. 
The complexity level is elevated because it is aimed at people with a specific background. This bulletin is prepared in the style of a technical report that describes and comments on the latest update of the monitoring results.

The main purposes of such bulletin are to (i) supply a complete description of the results obtained by the monitoring network in the considered period, (ii) identify and validate eventual trend changes with respect to the previous period and to the same period in previous years, and (iii) to audit the results in terms of eventual updates of the current monitoring network.

The third proposed bulletin is the Operative Monography. This document was designed to host with a standard format all the available information about the monitored landslide. The ICAO (International Civil Aviation Organization) operation manual inspires the Operative Monography structure. A complete description of this document is described in Giordan et al. [53].

\section{LANDMON Improvement and Application to Several Case Studies}

The presented approach is the product of many years of experience in the management of emergencies of slope instabilities, as well as other natural and anthropic hazards. Table 1 summarizes some of the most representative case studies were our system was applied and the improvement that we added step by step. The following case studies are listed in the table: Paganica fault [55], Montaguto earthflow [5,24,40], Costa Concordia wreck [48,56], Mont de La Saxe rockslide [7,41-43,49], Calatabiano landslide [21], and Ponzano landslide [20,57]. The main characteristics of each emergency (year, type, elements at risk) are presented. Furthermore, we listed the LANDMON modules applied to each case. The evolution of LANDMON can be noticed, as more and more modules were implemented over the years and applied on the new cases.

The emergency of Mont de La Saxe (2014) represents the first complete test bench for our system, as the complexity of monitoring network and the availability of various types of monitoring data allowed the development of the complete set of modules.

Mont de La Saxe is a large and complex slope instability located in the region of the Aosta Valley in northern Italy. Its unstable volume is of ca. $8 \times 10^{6} \mathrm{~m}^{3}[7,51]$, and it hazards a part of Courmayeur municipality and access road to the Mont Blanc Tunnel, an important connection for trans-Alpine transport. Due to these characteristics, the continuous and automatic monitoring of surface displacement has started in 2009.

Some examples of application for La Saxe case can be found in the present manuscript. Figure 3 shows the results of failure range forecasting module. Figure 4 presents, as an example of communication strategy, a daily single-page bulletin (developed in 2014, validated, and automatized in 2017). Figure 6 shows the application of automatic data processing and communication strategy.

Table 1. Temporal development of the system.

\begin{tabular}{|c|c|c|c|c|c|c|c|}
\hline \multirow[b]{3}{*}{ Year } & \multicolumn{7}{|c|}{ Emergency Name } \\
\hline & \multirow{2}{*}{$\begin{array}{c}\text { Paganica Fault } \\
2009\end{array}$} & \multirow{2}{*}{$\begin{array}{c}\text { Montaguto } \\
2010\end{array}$} & \multirow{2}{*}{\begin{tabular}{|c|}
$\begin{array}{c}\text { Costa } \\
\text { Concordia } \\
\text { Wreck }\end{array}$ \\
2012 \\
\end{tabular}} & \multicolumn{2}{|c|}{ Mont de La Saxe } & \multirow{2}{*}{$\begin{array}{c}\text { Calatabiano } \\
2015\end{array}$} & \multirow{2}{*}{$\begin{array}{c}\text { Ponzano } \\
2017\end{array}$} \\
\hline & & & & 2013 & 2014 & & \\
\hline Type & $\begin{array}{l}\text { Post-earthquake } \\
\text { fault movement }\end{array}$ & Earthflow & Vessel wreck & \multicolumn{2}{|c|}{ Rockslide } & Landslide & Landslide \\
\hline Elements at risk & $\begin{array}{c}\text { Main water } \\
\text { pipeline of } \\
\text { L'Aquila city }\end{array}$ & $\begin{array}{l}\text { National road } \\
\text { and railway }\end{array}$ & $\begin{array}{c}\text { Coastal } \\
\text { environment } \\
\text { and seawater }\end{array}$ & \multicolumn{2}{|c|}{$\begin{array}{l}\text { Inhabited zones, } \\
\text { access road to Mont } \\
\text { Blanc Tunnel }\end{array}$} & $\begin{array}{l}\text { Main water } \\
\text { pipeline of } \\
\text { Messina city }\end{array}$ & $\begin{array}{c}\text { Old town of } \\
\text { Ponzano village }\end{array}$ \\
\hline \multicolumn{8}{|c|}{ Applied modules } \\
\hline $\begin{array}{l}\text { automatic data } \\
\text { acquisition and } \\
\text { transfer }\end{array}$ & $\mathrm{x}$ & $\mathrm{x}$ & $\mathrm{x}$ & $\mathrm{x}$ & $\mathrm{x}$ & $x$ & $\mathrm{x}$ \\
\hline $\begin{array}{l}\text { automatic data } \\
\text { processing }\end{array}$ & & $\mathrm{x}$ & $\mathrm{x}$ & $\mathrm{x}$ & $x$ & $\mathrm{x}$ & $\mathrm{x}$ \\
\hline $\begin{array}{l}\text { on-line data } \\
\text { publication }\end{array}$ & & $\mathrm{x}$ & $\mathrm{x}$ & $\mathrm{x}$ & $x$ & $x$ & $\mathrm{x}$ \\
\hline
\end{tabular}


Table 1. Cont.

\begin{tabular}{|c|c|c|c|c|c|c|c|}
\hline & \multicolumn{7}{|c|}{ Emergency Name } \\
\hline & Paganica Fault & Montaguto & $\begin{array}{l}\text { Costa } \\
\text { Concordia } \\
\text { Wreck }\end{array}$ & Mor & axe & Calatabiano & Ponzano \\
\hline threshold based EW & & & $\mathrm{x}$ & $x$ & $x$ & $\mathrm{x}$ & $x$ \\
\hline $\begin{array}{l}\text { time failure } \\
\text { forecasting }\end{array}$ & & & & $\mathrm{x}$ & $\mathrm{x}$ & $\mathrm{x}$ & $\mathrm{x}$ \\
\hline $\begin{array}{l}\text { failure range } \\
\text { forecasting }\end{array}$ & & & & & $\mathrm{x}$ & $\mathrm{x}$ & $\mathrm{x}$ \\
\hline $\begin{array}{c}\text { Communication } \\
\text { strategy }^{1}\end{array}$ & & & & & $x$ & $\mathrm{x}$ & $\mathrm{x}$ \\
\hline
\end{tabular}

\section{Discussion}

In the last decades, the development of complex monitoring systems was focused on the technological improvements, which enabled quick automatic data acquisition, and dissemination of warnings and monitoring results. RTS, GPS, and GB-InSAR are only a few examples of possible instruments that can be adopted for the acquisition of physical variables and used for monitoring network architecture. Currently, monitoring systems are also used to support decision-makers and to inform population at risk.

The large availability of automatic and reliable monitoring sensors triggered the diffusion of EWSs. Modern monitoring systems provide a large amount of accurate measures at high sampling rates, so they are widely used to set early warning thresholds. However, the use of threshold-based approaches is characterized by the well-known difficulty to establish the threshold levels. These values are often conservative, and their underestimated values can produce reiterated alerts/alarms without a real failure. If the analyzed variable (e.g., superficial displacement or its derivative) exceeds the predefined threshold without real changes in the stability of the slope, the management procedure can reach a critical phase, which can be worsened by continuous alarms over a long period. The solution to avoid such a critical phase may be the revision of threshold values, or the use of supplementary models that can be useful in these particular conditions. As introduced before, LANDMON incorporates failure-forecasting model dedicated to early warning purposes (see Section 2.2.2).

To forecast ToF, we combined inverse velocity and statistic methods, thus the results should be always interpreted with regard to probability. This is why, in our opinion, describing a time range when the failure may occur is more adequate than trying to define an exact time of failure. Our goal was to develop an efficient module for LANDMON, which helps in near-real time the management of the early warning systems in the most critical phases and provides as many information as possible about landslide status during the emergencies. However, the aim of such EWSs is to support decision-makers, not to replace them. Technicians must first consult the results of the monitoring network and later associate them with other factors as weather conditions, previous landslide behavior, and experience in order to adopt an adequate decision.

The availability of large amount of near-real time monitoring data can be an advantage on one side, but on the other, it can create issues related to the management and to the processing of these data. LANDMON has been developed to deal with this large influx of data. Moreover, LANDMON recognizes another important aspect that often underestimated by classical technological solutions: the dissemination of results and the management of the available data.

The management of hazard monitoring networks is an interdisciplinary activity due to variety of involved people (engineers, geologists, technicians, politicians, council members, population, etc.). All these people participate (directly and indirectly) in this process, thus the collaboration among them is necessary. Our experience, in particular in the management of landslide emergencies as scientific advisor of National Civil Protection Agency, evidenced that the lack of correct communication strategy for monitoring results dissemination can be critical. For this purpose, beside hardware and software 
developments, we focused on communication aspects. We developed an appropriate communication approach, which we adopted in LANDMON. The assumption of our communication strategy is that monitoring systems can be considered efficient only if all involved people are able to understand the results produced by these systems. From this point of view, LANDMON is not just a system composed of technological features but also an expression of the communication strategy that supplies different monitoring results representations according to the stakeholders' background.

As presented in Table 1, LANDMON is the result of many years of experience in the management and monitoring of various hazardous scenarios. We developed LANDMON mainly for applications in the field of geohazards like landslides [24,41], but we also considered other experiences as the hazard management in anthropic environment like open pit mines [58] or cultural heritage sites [59].

In many applications, LANDMON considers not only the natural process but also the stability of elements at risk like buildings and infrastructures, which are usually integrated within the instable areas. For example, the water pipeline of Paganica fault $[47,55]$ and Calatabiano case studies, as well as the buildings and retaining wall of the old town of Ponzano [20], were subject to monitoring together with main landslide evolution. Another example of unusual application of our system is the monitoring of Costa Concordia wreck [48].

The first case study shown in the Table 1 is Paganica fault (2009), when only the "automatic data acquisition and transfer" module was implemented. In the following years, due to growing social requirements and technological possibilities, we developed more modules in occasion of Montaguto, Costa Concordia and Mont de La Saxe (2013) case studies. The first complete LANDMON system was finally implemented for Mont de La Saxe (2014) case study, where we successfully applied our communication strategy during the emergency. Our complete system was later used to manage Calatabiano and Ponzano landslides.

\section{Conclusions}

In this paper, we presented LANDMON (LANDslides MOnitorng Network), a multidisciplinary solution for effective management of monitoring networks used for the complex landslides evolution control. The developed modular approach can be adopted also for others emergencies that should be managed using complex monitoring systems. We developed and tested this approach and its modules in several landslide-related emergencies like Montaguto or Mont de La Saxe.

The proposed method is a sequence of computerized tools and a more structured procedure that considers technological, computational, and communication aspects.

The first aspect of LANDMON considers a modular organization of applications, which can be configured according to the characteristics of the monitored site. These features guarantee flexibility in application for various scenarios, not only related to landslide monitoring, but also to the monitoring of other hazard types, like open pit mines, buildings, and dams. All developed modules may be executed automatically and queried in the main process to perform the cycle in automatic mode from acquisition to dissemination.

Following the technological aspect, the system development focused on a more complex management of early warning by integrating a failure forecast modeling. This module provides a prediction about possible evolution of the landslide when the "classical" threshold-based alarm level is exceeded. Additionally, the supplementary alarm threshold is determined based on reliability of the implemented model.

The last aspect of LANDMON is the communication strategy. The proposed approach considers the needs and backgrounds of users, as it follows the principles of usable science by translating complex data sets into adequate representations for the receivers. This communication strategy carefully considers the population at risk, which is the real end-user of monitoring systems, by providing a dedicated solution. In particular, the last monitoring results are disseminated by means of a single-page informative bulletin where the landslide status is presented using infographic techniques to obtain clear, illustrative, and quickly interpretative overview. The use of user-friendly 
representations of complex data is a key point for a correct communication of real risk level that should be easily transmitted to the population, especially during emergencies.

Therefore, LANDMON is a complex, automatic, complete, and self-contained system designed for efficient acquisition, analysis, and appropriate representation and dissemination of the monitoring data. This system merges engineering with communication aspects, improving the effectiveness of the management of monitoring network and providing a sustainable risk management approach for active landslides in urbanized areas.

Author Contributions: This paper represents a result of collaborative teamwork. Conceptualization, methodology, software development and validation, D.G., A.W. and P.A.; manuscript writing and revising D.G. and A.W.

Funding: This research received no external funding.

Conflicts of Interest: The authors declare no conflict of interest.

\section{References}

1. Wieczorek, G.F.; Snyder, J.B. Monitoring slope movements. In Geological Monitoring; Young, R., Norby, L., Eds.; Geological Society of America: Boulder, CO, USA, 2009; pp. 245-271.

2. Frodella, W.; Ciampalini, A.; Bardi, F.; Salvatici, F.; Di Traglia, F.; Basile, G.; Casagli, N. A method for assessing and managing landslide residual hazard in urban areas. Landslides 2018, 15, 183-197. [CrossRef]

3. Vranken, L.; Vantilt, G.; Van Den Eeckhaut, M.; Vandekerckhove, L.; Poesen, J. Landslide risk assessment in a densely populated hilly area. Landslides 2015, 12, 787-798. [CrossRef]

4. Cotecchia, V. The second Hans Cloos lecture. Experience drawn from the great Ancona landslide of 1982. Bull. Eng. Geol. Environ. 2006, 65, 1. [CrossRef]

5. Giordan, D.; Allasia, P.; Manconi, A.; Baldo, M.; Santangelo, M.; Cardinali, M.; Corazza, A.; Albanese, V.; Lollino, G.; Guzzetti, F. Morphological and kinematic evolution of a large earthflow: The Montaguto landslide, southern Italy. Geomorphology 2013, 187, 61-79. [CrossRef]

6. Ferrigno, F.; Gigli, G.; Fanti, R.; Intrieri, E.; Casagli, N. GB-InSAR monitoring and observational method for landslide emergency management: The Montaguto earthflow (AV, Italy). Nat. Hazards Earth Syst. Sci. 2017, 17, 845. [CrossRef]

7. Crosta, G.B.; Lollino, G.; Paolo, F.; Giordan, D.; Andrea, T.; Carlo, R.; Davide, B. Rockslide monitoring through multi-temporal LiDAR DEM and TLS data analysis. In Engineering Geology for Society and Territory-Volume 2; Springer: Cham, Switzerland, 2015; pp. 613-617.

8. Frigerio, S.; Schenato, L.; Bossi, G.; Cavalli, M.; Mantovani, M.; Marcato, G.; Pasuto, A. A web-based platform for automatic and continuous landslide monitoring: The Rotolon (Eastern Italian Alps) case study. Comput. Geosci. 2014, 63, 96-105. [CrossRef]

9. Del Ventisette, C.; Casagli, N.; Fortuny-Guasch, J.; Tarchi, D. Ruinon landslide (Valfurva, Italy) activity in relation to rainfall by means of GBInSAR monitoring. Landslides 2012, 9, 497-509. [CrossRef]

10. Jaboyedoff, M.; Ornstein, P.; Rouiller, J.-D. Design of a geodetic database and associated tools for monitoring rock-slope movements: The example of the top of Randa rockfall scar. Nat. Hazards Earth Syst. Sci. 2004, 4, 187-196. [CrossRef]

11. Squarzoni, C.; Delacourt, C.; Allemand, P. Differential single-frequency GPS monitoring of the La Valette landslide (French Alps). Eng. Geol. 2005, 79, 215-229. [CrossRef]

12. Malet, J.-P.; Maquaire, O.; Calais, E. The use of Global Positioning System techniques for the continuous monitoring of landslides: Application to the Super-Sauze earthflow (Alpes-de-Haute-Provence, France). Geomorphology 2002, 43, 33-54. [CrossRef]

13. Travelletti, J.; Malet, J.-P. Characterization of the 3D geometry of flow-like landslides: A methodology based on the integration of heterogeneous multi-source data. Eng. Geol. 2012, 128, 30-48. [CrossRef]

14. Ayalew, L.; Yamagishi, H.; Marui, H.; Kanno, T. Landslides in Sado Island of Japan: Part I. Case studies, monitoring techniques and environmental considerations. Eng. Geol. 2005, 81, 419-431. [CrossRef]

15. Parise, M.; Coe, J.A.; Savage, W.Z.; Varnes, D.J. The Slumgullion landslide (southwestern Colorado, USA): Investigation and monitoring. In Proceedings of the International Conference FLOWS, Sorrento, Italy, 11-13 May 2003; pp. 11-13. 
16. Angeli, M.-G.; Pasuto, A.; Silvano, S. A critical review of landslide monitoring experiences. Eng. Geol. 2000, 55, 133-147. [CrossRef]

17. Gili, J.A.; Corominas, J.; Rius, J. Using Global Positioning System techniques in landslide monitoring. Eng. Geol. 2000, 55, 167-192. [CrossRef]

18. Tagliavini, F.; Mantovani, M.; Marcato, G.; Pasuto, A.; Silvano, S. Validation of landslide hazard assessment by means of GPS monitoring technique? a case study in the Dolomites (Eastern Alps, Italy). Nat. Hazards Earth Syst. Sci. 2007, 7, 185-193. [CrossRef]

19. Arbanas, Ž.; Sassa, K.; Marui, H.; Mihalić, S.; Eberhardt, E. Comprehensive monitoring system on the Grohovo Landslide, Croatia. In Landslides and Engineered Slopes: Protecting Society through Improved Understanding, Proceedings of the 11th International \& 2nd North American Symposium on Landslides, Banff, Canada, 2-8 June 2012; Taylor \& Francis: London, UK; pp. 1441-1447.

20. Allasia, P.; Baldo, M.; Giordan, D.; Godone, D.; Wrzesniak, A.; Lollino, G. Near Real Time Monitoring Systems and Periodic Surveys Using a Multi Sensors UAV: The Case of Ponzano Landslide. In Proceedings of the IAEG/AEG Annual Meeting, San Francisco, CA, USA, 2019.

21. Lombardi, L.; Nocentini, M.; Frodella, W.; Nolesini, T.; Bardi, F.; Intrieri, E.; Carlà, T.; Solari, L.; Dotta, G.; Ferrigno, F.; et al. The Calatabiano landslide (southern Italy): Preliminary GB-InSAR monitoring data and remote 3D mapping. Landslides 2017, 14, 685-696. [CrossRef]

22. Simeoni, L.; Mongiovì, L. Inclinometer monitoring of the Castelrotto landslide in Italy. J. Geotech. Geoenviron. Eng. 2007, 133, 653-666. [CrossRef]

23. Allasia, P.; Lollino, G.; Godone, D.; Giordan, D. Deep displacements measured with a robotized inclinometer system. In Proceedings of the 10th International Symposium on Field Measurements in Geomechanics, Rio de Janeiro, Brasil, 16-20 July 2018.

24. Allasia, P.; Manconi, A.; Giordan, D.; Baldo, M.; Lollino, G. ADVICE: A new approach for near-real-time monitoring of surface displacements in landslide hazard scenarios. Sensors 2013, 13, 8285-8302. [CrossRef] [PubMed]

25. Eberhardt, E.; Watson, A.; Loew, S. Improving the interpretation of slope monitoring and early warning data through better understanding of complex deep-seated landslide failure mechanisms. In Landslides and Engineered Slopes; Taylor \& Francis: London, UK, 2008; pp. 39-51.

26. Intrieri, E.; Gigli, G.; Mugnai, F.; Fanti, R.; Casagli, N. Design and implementation of a landslide early warning system. Eng. Geol. 2012, 147, 124-136. [CrossRef]

27. Bell, R.; Glade, T.; Thiebes, B.; Jäger, S.; Krummel, H.; Janik, M.; Holland, R. Modelling and Web Processing of Early Warning. Available online: https:/ /homepage.univie.ac.at/thomas.glade/Publications/BellEtAl2009. pdf (accessed on 12 February 2019).

28. Michoud, C.; Bazin, S.; Blikra, L.H.; Derron, M.-H.; Jaboyedoff, M. Experiences from site-specific landslide early warning systems. Nat. Hazards Earth Syst. Sci. 2013, 13, 2659-2673. [CrossRef]

29. Glade, T.; Nadim, F. Early warning systems for natural hazards and risks. Nat. Hazards 2014, 70, 1669-1671. [CrossRef]

30. Thiebes, B.; Glade, T. Landslide early warning systems-Fundamental concepts and innovative applications. In Landslides and Engineered Slopes: Experience, Theory and Practice, Proceedings of the 12th International Symposium on Landslides, Napoli, Italy, 12-19 June 2016; Aversa, S., Cascini, L., Picarelli, L., Scavia, C., Eds.; Taylor \& Francis: London, UK; pp. 12-19.

31. Di Biagio, E.; Kjekstad, O. Early Warning, Instrumentation and Monitoring Landslides. In Proceedings of the 2nd Regional Training Course, RECLAIM II, Phuket, Thailand, 29 January-2 February 2007. Available online: http://www.adpc.net/V2007/Programs/UDRM/PROGRAMS_PROJECTS/RECLAIMIII/ Downloads/RECLAIMProceedings(1).pdf (accessed on 12 February 2019).

32. Balis, B.; Kasztelnik, M.; Bubak, M.; Bartynski, T.; Gubała, T.; Nowakowski, P.; Broekhuijsen, J. The urbanflood common information space for early warning systems. Procedia Comput. Sci. 2011, 4, 96-105. [CrossRef]

33. Alberti, S.; Crosta, G.B.; Rivolta, C. Statistical analysis of displacement rate for definition of EW thresholds applied to two case studies. In Proceedings of the Workshop on World Landslide Forum, Ljubljana, Slovenia, 2017; pp. 285-292.

34. Crosta, G.; Agliardi, F. How to obtain alert velocity thresholds for large rockslides. Phys. Chem. Earth Parts $A B C$ 2002, 27, 1557-1565. [CrossRef] 
35. Bhandari, R. Some lessons in the investigation and field monitoring of landslides. In Proceedings of the 5th International Symposium on Landslides, Lausanne, Switzerland, 10-15 July 1988; pp. 1435-1457.

36. Carlà, T.; Intrieri, E.; Di Traglia, F.; Nolesini, T.; Gigli, G.; Casagli, N. Guidelines on the use of inverse velocity method as a tool for setting alarm thresholds and forecasting landslides and structure collapses. Landslides 2017, 14, 517-534. [CrossRef]

37. Saito, M. Forecasting the Time of Occurrence of a Slope Failure. 1965. Available online: https://www.issmge. org/uploads/publications/1/39/1965_02_0116.pdf (accessed on 12 February 2019).

38. Fukuzono, T. A new method for predicting the failure time of a slope. In Proceedings of the 4th International Conference and Field Workshop on Landslide, Tokyo, Japan, 23-31 August 1985; pp. 145-150.

39. Federico, A.; Popescu, M.; Elia, G.; Fidelibus, C.; Internò, G.; Murianni, A. Prediction of time to slope failure: A general framework. Environ. Earth Sci. 2012, 66, 245-256. [CrossRef]

40. Manconi, A.; Allasia, P.; Giordan, D.; Baldo, M.; Lollino, G.; Corazza, A.; Albanese, V. Landslide 3D Surface Deformation Model Obtained Via RTS Measurements. In Proceedings of the Second World Landslide Forum, Rome, Italy, 3-7 October 2011.

41. Giordan, D.; Manconi, A.; Allasia, P.; Bertolo, D. Brief Communication: On the rapid and efficient monitoring results dissemination in landslide emergency scenarios: The Mont de La Saxe case study. Nat. Hazards Earth Syst. Sci. 2015, 15, 2009-2017. [CrossRef]

42. Manconi, A.; Giordan, D. Landslide failure forecast in near-real-time. Geomat. Nat. Hazards Risk 2016, 7, 639-648. [CrossRef]

43. Wrzesniak, A.; Giordan, D. Development of an algorithm for automatic elaboration, representation and dissemination of landslide monitoring data. Geomat. Nat. Hazards Risk 2017, 8, 1898-1913. [CrossRef]

44. UNISDR. Global Survey of Early Warning Systems. 2006. Available online: https://www.unisdr.org/2006/ ppew/info-resources/ewc3/Global-Survey-of-Early-Warning-Systems.pdf (accessed on 12 February 2019).

45. UNISDR. The Sendai Framework for Disaster Risk Reduction 2015-2030. 2015. Available online: https: / / www.preventionweb.net/files/43291_sendaiframeworkfordrren.pdf (accessed on 12 February 2019).

46. Garcia, C.; Fearnley, C.J. Evaluating critical links in early warning systems for natural hazards. Environ. Hazards 2012, 11, 123-137. [CrossRef]

47. Lollino, G.; Manconi, A.; Giordan, D.; Allasia, P.; Baldo, M. Infrastructure in geohazard contexts: The importance of automatic and near-real-time monitoring. In Environmental Security of the European Cross-Border Energy Supply Infrastructure; Springer: Dordrecht, The Netherlands, 2015; pp. 73-89.

48. Manconi, A.; Allasia, P.; Giordan, D.; Baldo, M.; Lollino, G. Monitoring the stability of infrastructures in an emergency scenario: The "Costa Concordia" vessel wreck. In Global View of Engineering Geology and the Environment; Taylor \& Francis Group: London, UK, 2013.

49. Manconi, A.; Giordan, D. Landslide early warning based on failure forecast models: The example of the Mt. de La Saxe rockslide, northern Italy. Nat. Hazards Earth Syst. Sci. 2015, 15, 1639-1644. [CrossRef]

50. Crosta, G.; Agliardi, F. Failure forecast for large rock slides by surface displacement measurements. Can. Geotech. J. 2003, 40, 176-191. [CrossRef]

51. Crosta, G.; Di Prisco, C.; Frattini, P.; Frigerio, G.; Castellanza, R.; Agliardi, F. Chasing a complete understanding of the triggering mechanisms of a large rapidly evolving rockslide. Landslides 2014, 11, 747-764. [CrossRef]

52. Efron, B. Bootstrap methods: Another look at the jackknife. 1979. Available online: http://jeti.uni-freiburg. de/studenten_seminar/stud_sem_SS_09/EfronBootstrap.pdf (accessed on 12 February 2019).

53. Giordan, D.; Cignetti, M.; Wrzesniak, A.; Allasia, P.; Bertolo, D. Operative Monographies: Development of a New Tool for the Effective Management of Landslide Risks. Geosciences 2018, 8, 485. [CrossRef]

54. Smiciklas, M. The Power of Infographics: Using Pictures to Communicate and Connect with Your Audiences; Que Publishing: Indianapolis, IN, USA, 2012.

55. Manconi, A.; Giordan, D.; Allasia, P.; Baldo, M.; Lollino, G. Surface displacements following the Mw 6.3 L'Aquila earthquake: One year of continuous monitoring via Robotized Total Station. Ital. J. Geosci. 2012, 131, 403-409.

56. Raspini, F.; Moretti, S.; Fumagalli, A.; Rucci, A.; Novali, F.; Ferretti, A.; Prati, C.; Casagli, N. The COSMO-SkyMed constellation monitors the Costa Concordia wreck. Remote Sens. 2014, 6, 3988-4002. [CrossRef] 
57. Solari, L.; Raspini, F.; Del Soldato, M.; Bianchini, S.; Ciampalini, A.; Ferrigno, F.; Tucci, S.; Casagli, N. Satellite radar data for back-analyzing a landslide event: The Ponzano (Central Italy) case study. Landslides 2018, 15, 773-782. [CrossRef]

58. Allasia, P.; Giordan, D.; Lollino, G.; Cravero, M.; Iabichino, G.; Bianchi, N.; Monticelli, F. Monitoring and Computations on a Landslide in an Open Pit Mine; American Rock Mechanics Association: Alexandria, VA, USA, 2009.

59. Margottini, C.; Corominas, J.; Crosta, G.B.; Frattini, P.; Gigli, G.; Iwasaky, I.; Lollino, G.; Marinos, P.; Scavia, C.; Sonnessa, A. Landslide hazard assessment, monitoring and conservation of Vardzia monastery complex. In Engineering Geology for Society and Territory-Volume 8; Springer: Cham, Switzerland, 2015; pp. 293-297.

2019 by the authors. Licensee MDPI, Basel, Switzerland. This article is an open access article distributed under the terms and conditions of the Creative Commons Attribution (CC BY) license (http://creativecommons.org/licenses/by/4.0/). 